\title{
LOS DESAFÍOS DE LA GLOBALIZACIÓN EN AMÉRICA LATINA: ¿ESTADO O REGIÓN? ${ }^{1}$
}

\author{
The Challenges of Globalization in Latin America: State or Region?
}

\author{
Lorena Oyarzún Serrano*
}

\begin{abstract}
RESUMEN
El proceso de globalización plantea interrogantes sobre la capacidad del Estado de representar a su población; de enfrentar amenazas externas; de resolver eficientemente demandas de carácter transnacional cada vez más frecuentes y de la supervivencia ¿o no de su hegemonía? En esta línea, este artículo analiza los efectos de la globalización en el Estado, especialmente en América Latina, y en la soberanía, principio constituyente del Orden Westfaliano. Se busca responder si el Estado mantiene su vigencia como organización política, considerando que las personas muchas veces presentan lealtades en comunidades internacionales, regionales y domésticas y este podría competir con organizaciones regionales. Se argumenta que si bien las regiones supraestatales surgen para gestionar la interdependencia y equilibrar intereses y lealtades, a veces superpuestos en la dimensión de lo local, regional y global, el Estado persiste. Del mismo modo, se sostiene que las tendencias de integración, así como las de fragmentación, son 'dos caras de la misma moneda' al ser ambas respuestas ante la mayor incertidumbre del sistema. Para desarrollar estas ideas, el texto se organiza de la siguiente manera: primero se mencionan los rasgos distintivos de la globalización. Luego se estudia la construcción del Estado y la soberanía en perspectiva histórica; su relación con las tendencias de integración, desintegración y nacionalismo. Finalmente, se consideran las posibilidades de la región en un escenario de interdependencia.
\end{abstract}

Palabras clave: Globalización, Estado, región, soberanía, América Latina.

\footnotetext{
${ }^{1}$ Este trabajo se desarrolló en el marco del Núcleo Milenio de Ciencias Sociales, Proyecto NS100014, "Estudio de la Estatalidad y la Democracia en América Latina", 2011-2014.

* Instituto de Asuntos Públicos, Universidad de Chile. Santiago, Chile. Correo electrónico: loyarzus@ iap.uchile.cl
} 


\begin{abstract}
The process of globalization raises questions about the State's ability to represent its population, to address external threats, to efficiently resolve increasingly frequent transnational demands and the survival or not of its hegemony. In this article I analyze the effect of globalization in the State, especially in Latin America, and in sovereignty, constituent principle of the Westphalian Order. I seek to answer if the State maintains its validity as a political organization, considering that often people present loyalties in international, regional and domestic communities and it could compete with regional organizations. I argue that supranational regions emerge as a strategy for managing interdependence and to balance interests and loyalties sometimes overlapping on the local, regional and global dimension. At the same time, I hold that integration trends such as fragmentation ones are 'two sides of the same coin', both are responses to the greater uncertainty of the system. To develop these ideas, I organize the text as follows, first I mention the distinctive features of globalization. Then I study the construction of the State and sovereignty in historical perspective and its relationship with integration, disintegration and nationalism trends. Finally, I consider region's posibilities in an interdependence scenary.
\end{abstract}

Keywords: Globalization, State, Region, Sovereignty, Latin America.

\title{
Introducción
}

La globalización refleja "un cambio o transformación en la escala de la organización humana que enlaza comunidades distantes y expande el alcance de las relaciones de poder a través de regiones y continentes de todo el mundo" (Held y McGrew, 2003: 13), generando diversos efectos en la sociedad internacional y, de especial interés para este estudio, en el Estado y los proyectos regionales de Latinoamérica. Para Keohane y Nye (2000) la globalización implica un aumento de la interdependencia (globalismo), pero con dos características distintivas: redes de conexiones múltiples y distancias multicontinentales. En tanto, Stiglitz (2002) sostiene que el globalismo se ha reforzado por los avances tecnológicos que han permitido la disminución de los costes del transporte y de la comunicación. Al mismo tiempo, los flujos de bienes, servicios, capitales e información enfrenten cada vez menos barreras artificiales a través de las fronteras. No obstante, el movimiento de personas 
sigue siendo una preocupación de los gobiernos que la mayoría de las veces pretende controlar y/o suprimir² (Kymlicka, 2006; Iranzo, 2016).

Se distinguen tres dimensiones de la globalización, la económica asociada al desarrollo de la revolución tecnológica e informática, conjuntamente con el accionar de multinacionales y las inversiones en el extranjero. La política, vinculada a la primacía occidental-estadounidense, así como también las organizaciones internacionales, regionales y redes transgubernamentales. Y la globalización cultural relacionada con la circulación de los productos culturales, que para algunos presentaría enormes desafíos ante la uniformidad y para otros, en cambio, potenciaría las reivindicaciones de singularidad (Hoffmann, 2002).

Held (1997) y Meyer (2012), por su parte, sostienen que con el proceso de globalización los Estados estarían perdiendo sus rasgos esenciales asociados a la capacidad de ejercer la soberanía tradicional y mantener la gobernanza. Pues, la naturaleza transnacional de los temas en la agenda, como medio ambiente, terrorismo, migraciones, derechos humanos, pandemias, entre otros, desafía la capacidad de los Estados para abordarlos. Asimismo, los Estados se verían sobrepasados al intentar concentrar la toma de decisición en todos los niveles. En este contexto, este artículo estudia los efectos de la globalización en América Latina, particularmente en el Estado Westfaliano y la soberanía. Se busca responder si ¿se mantiene la vigencia del Estado en América Latina, considerando que las personas muchas veces presentan lealtades superpuestas en comunidades internacionales, regionales y domésticas y que debe competir con organizaciones regionales?

\footnotetext{
${ }^{2}$ Existen variados ejemplos contemporáneos de esta situación, desde las restrictivas políticas migratorias enunciadas por la administración de Donald Trump en Estados Unidos ante el flujo de migrantes; la denominada crisis de los refugiados sirios en Europa o las discusiones sobre el enfoque de seguridad o de derechos ante la movilidad humana que se está iniciando, incluso en países como Chile, que solo recientemente se han convertido en receptores de migración intrarregional.
} 
Se argumenta que las regiones de carácter supraestatal han surgido para gestionar temáticas transnacionales y problemas escasamente abordados bajo el paradigma estadocéntrico, lo que pueden lograr a través de la gobernanza multinivel. Asimismo, se sostiene que tanto las tendencias de integración, así como las de fragmentación y el nacionalismo son respuestas distintas al mismo fenómeno: interdependencia asimétrica e incertidumbre del sistema. Para desarrollar estas ideas, se aplica una perspectiva constructivista con el fin de distinguir y discutir en torno a las ideas que compiten, los procesos de transferencia de lealtades y redefinición de intereses. En este sentido, el constructivismo es útil como herramienta analítica, dado que se centra en la realidad social y el papel de las ideas. Su agenda de investigación incluye temáticas asociadas a la creación de normas, instituciones, discursos, procesos deliberativos y/o constitutivos y sus significados intersubjetivos (Christiansen, Jorgensen y Wiener, 2001).

En el ámbito de las Relaciones Internacionales, el constructivismo reconoce el poder de las instituciones multilaterales, a la vez que advierte la continuidad entre la toma de decisiones a nivel doméstico e internacional (Haas, 2001). Del mismo modo, proporciona herramientas para examinar el proceso de construcción de la soberanía, mediado por la interacción entre actores y estructuras, centrándose en las modificaciones de significado y la irrupción de diferentes formas de soberanía. Se asume una mutua formación entre las estructuras sociales y los actores (Wendt, 1987). "Para los constructivistas los objetos de nuestro conocimiento no son independientes de nuestras interpretaciones y lenguaje. El significado de la conducta humana reside precisamente en el hecho de que pueda ser entendido por otros seres humanos" (Oyarzún, 2011: 64).

El texto se organiza en tres partes, primero se debate la construcción del Estado en perspectiva histórica, dando énfasis al principio de soberanía. Del mismo modo, se aborda la construcción del Estado latinoamericano. 
Posteriormente, se analizan tendencias de integración, así como de fragmentación, nacionalismos y emergencia de regiones para gestionar los efectos de la globalización. Finalmente, se enuncian las conclusiones.

\section{Ideas y principios subyacentes en la construcción del Estado}

El Estado es un tipo de organización política, hoy dominante en la sociedad internacional, que emergió durante el siglo XVII. El sistema de Estados europeo, también denominado "Orden o Sistema Westfaliano", hace referencia a la Paz de Westfalia (1648) que puso fin a la Guerra de los Treinta Años $^{3}$ y es punto de partida en su construcción. Con los Tratados de Osnabrück, mayoritariamente para los combatientes protestantes, y de Münster, para los participantes católicos, se selló la paz en 1648, convirtiéndose además en una primera versión de Conferencia de Paz Paneuropea. Ambos tratados registraron el intercambio territorial, compensaciones por daños de guerra, particiones territoriales, secularizaciones de ciudades, entre otros (Holsti, 2004).

Del mismo modo, por medio de los Acuerdos de Osnabrük y Münster se limitó el poder eclesiástico, otorgando potestad a varios príncipes para resolver problemas seculares y se prohibió a Estados y príncipes convertir uno a otro en súbdito. Entre el siglo XVI y XVII, Francisco de Vitoria y Francisco Suárez, dos destacados teólogos-juristas, argumentaron que ni el Papa ni el Sacro Emperador Romano podían sobreponerse a las leyes civiles de Castilla. Su razonamiento se fundó en que el derecho del príncipe a gobernar es traspasado directamente desde Dios y no a través del Papa. Estas ideas, revolucionarias para la época, implicaban que la Iglesia no tenía potestad sobre cuestiones de

\footnotetext{
${ }^{3}$ La Guerra de los Treinta Años (1618-1648) involucró en un principio a partidarios de la reforma y la contrarreforma, posteriormente participaron otros actores por motivos no estrictamente religiosos en una amplia zona de Europa Central. Entre sus efectos, destaca el fin de la supremacía de la Casa de los Habsburgo y la descentralización del Sacro Imperio Romano.
} 
legislación y autoridad civil. En esa misma línea, Jean Bodin planteó que la soberanía, poder ilimitado e indivisible de hacer leyes, residía en el Estado y el soberano solo era la autoridad legítima en virtud de su cargo y no de su persona (Biersteker, 2008; Holsti, 2004; Held, 1997).

La posibilidad de imaginar una nación soberana solo se produjo cuando se modificaron tres concepciones que ordenaban el mundo, la comunidad religiosa, la dinastía monárquica y la concepción del tiempo como sacro, supeditado a un orden y sentido divino (Anderson, 1993). De esta manera, el Sistema Westfaliano se fundamentó en cuatro principios: a) Autoridad, entendida como el derecho mutuamente reconocido y legitimado para que un actor realice determinadas actividades, el denominado 'derecho a gobernar'. b) Soberanía, vinculada al control de las fronteras y la capacidad de excluir estructuras de autoridad externa en el propio territorio, además del derecho a decidir y contar con reconocimiento internacional. c) Territorialidad, organización política del espacio, y d) La ciudadanía, referida a la pertenencia a una comunidad política (Krasner, 2001; Caporaso, 2000).

Los Estados podrán crear derecho, ejecutar la ley y resolver disputas en un territorio definido. Las controversias entre ellos se resuelven, en última instancia, por medio del uso de la violencia. A finales del siglo XVIII se limitó el derecho de conquista territorial. Así es como en el Congreso de Viena (1815) se estipuló que la soberanía requiere del consentimiento del vencido y no existe una total libertad de acción en territorios extranjeros ${ }^{4}$. Más adelante, con el desarrollo del nacionalismo y de la doctrina de autodeterminación de los pueblos, se deslegitimó la práctica de la conquista. El Tratado de Versalles de 1919, que creó la Sociedad de las Naciones, tuvo como propósito principal

\footnotetext{
${ }^{4}$ El Congreso de Viena es convocado con el objetivo de reordenar las fronteras europeas que habían sido modificadas por las conquistas napoleónicas y restablecer las monarquías europeas. Del mismo modo, rechazan los objetivos de la Revolución Francesa y la emergencia de fuerzas nacionales que promueven la formación de Estados nacionales.
} 
proteger la soberanía, independencia e integridad territorial de sus miembros (Holsti, 2004; Held, 1997).

En este escenario, la soberanía, se convirtió en el pilar fundamental del sistema interestatal, ya que crea y mantiene a los Estados. Por medio de su reconocimiento ${ }^{5}$ se establece qué actores son legítimos, instituye un sistema legal entre iguales, santifica el principio de independencia, autonomía, integridad territorial y establece normas y principios que buscan otorgar predictibilidad a un sistema anárquico ${ }^{6}$, dando mayor transparencia y seguridad (Holsti, 2004; Caporaso, 2000). Para Holsti (2004) la soberanía es una categoría absoluta con principios fundacionales intactos, pese a admitir que sus interpretaciones, así como sus prácticas, se transforman con el tiempo. En esta línea, Krasner (2001) reconoce que la soberanía es afectada por el contexto histórico e identifica cuatro tipos de soberanía: 1) La westfaliana, entendida como la capacidad de excluir protagonistas externos en las estructuras de autoridad política del Estado; 2) La legal internacional, basada en el reconocimiento mutuo entre Estados soberanos; 3) La interna, que es la facultad de ejercer control dentro del propio Estado y 4) La interdependiente, relacionada con la habilidad de las autoridades públicas de regular flujos de información, capital, drogas, enfermedades, bienes, o contaminantes, entre otros.

La gran mayoría de los debates sobre la fortaleza, erosión o pérdida de la soberanía estatal en el siglo XXI se han centrado en la denominada soberanía interdependiente. Se analizan los efectos de la globalización en la capacidad

\footnotetext{
${ }^{5}$ Las prácticas de reconocimiento internacional han cambiado a través del tiempo. Después de la Segunda Guerra Mundial, las metrópolis dan reconocimiento a sus posesiones coloniales a pesar de que muchos de los nuevos Estados no ejercen el control efectivo sobre su territorio ni tampoco tienen instituciones domésticas estables. Con el fin del sistema bipolar, en cambio, se da relevancia a aspectos relacionados con el compromiso de los nuevos Estados a establecer instituciones políticas democráticas, garantizar el derecho de las minorías y establecer un sistema económico de libre mercado, por ejemplo en las ex constituyentes unidades de la Unión Soviética y Yugoslavia (Holsti, 2004).

${ }^{6}$ En Relaciones Internacionales, anarquía significa ausencia de una autoridad central y se explica por el principio de soberanía reconocido por los Estados. No obstante, la anarquía no implica, necesariamente, falta de orden y de jerarquías en el sistema internacional.
} 
de regular los flujos que genera la mayor interdependencia. Algunos autores sostienen que la interdependencia no disminuye la facultad del Estado de excluir a protagonistas externos ni su capacidad de dominio (Krasner, 2001). Ejemplo de ello, se observa cuando las autoridades estatales instauran medidas que promueven la censura, la limitación de libre circulación, la construcción de muros y fronteras o la utilización y acceso a datos privados de sus ciudadanos con la excusa de descartar amenazas a su seguridad. Otros más escépticos y sostienen que "La única forma en que la soberanía puede perderse hoy en día es a través de la conquista formal, anexión o por la amalgamación voluntaria" (Holsti, 2004: 137).

Sin embargo, la erosión de la soberanía se evidencia en la inhabilidad de los gobiernos para regular diversos movimientos en sus fronteras y por lo tanto al interior del territorio nacional. De esta manera, ningún Estado puede, de manera aislada, hacer frente a desafíos de carácter mundial como el calentamiento global; los movimientos de personas, ya sea en su dimensión de migrantes o como refugiados; el brote de una pandemia, por ejemplo la gripe aviar en 2003, pandemia gripal de 2009 o el virus Zika en 2016. Tampoco a los efectos de crisis económico-financieras que adquieren ribetes globales, la contaminación de los océanos o los grandes desastres naturales como terremotos, incendios o sequías prolongadas. De ahí la importancia de los organismos internacionales para centralizar información y coordinar la cooperación en la arena global. En este sentido, la Escuela Constructivista integra al análisis nociones de intersubjetividad y aprendizaje, asumiendo que tanto el Estado como la soberanía son construcciones sociales y por lo tanto son mutables. Biersteker (2008) propone que la conceptualización de la soberanía, al igual que la del Estado, no debe ser estática. 


\section{Construcción del Estado en América Latina}

En el Sistema Westfaliano el nacionalismo es la base del Estado-nación, este puede ser entendido como ideología o movimiento social. Si se concibe como ideología, proviene de las elites que exaltan la nación y sus valores en perjuicio de la alteridad, buscando consolidar un Estado que potencia las diferencias del grupo con los otros, ya sea a nivel cultural y/o histórico, convirtiéndose en una guía de cómo el mundo es y debería ser. Por otra parte, entendido como movimiento social promueve una identidad común, sentimientos de lealtad y pertenencia a una comunidad (Hoffmann, 1966).

El nacionalismo americano se vincula al romanticismo alemán en cuanto enuncia un discurso que concibe la nación como fuerza superior y expresión del 'espíritu nacional', destacando costumbres, historia e idioma común de los americanos. No obstante, los referentes ideológicos del movimiento independentista provienen de la Europa liberal que imagina un ciudadano libre, sin incorporar necesariamente la idea de nación. América recibe influencia de focos culturales externos con una amplia herencia cultural que "pasa a ser su patrimonio posible. Y desde allí surge, con Estados incipientes e inestables, el difícil proceso de construcción de las identidades nacionales" (Stuven, 1992: 43).

En el proceso de construcción del Estado en América Latina hay que considerar la herencia colonial y la implantación del modelo europeo. De esta manera, con la emancipación de la Monarquía Española, las elites y líderes de la independencia hispanoamericana debieron identificar y crear 'lo común' en los territorios liberados. La 'americanidad' se enunció como rasgo principal, exaltando el lugar de nacimiento como un factor inclusivo de ciudadanía. Varios de los Libertadores, influenciados por los acontecimientos que se producían en Europa y Estados Unidos, compartieron la filosofía de los derechos naturales, fundados en la naturaleza humana, proclamaron la soberanía popular y 
exigieron constituciones escritas reconociendo el principio de separación de poderes (Lynch, 2001).

Asimismo, promovieron una sociedad en la que todos los seres humanos -por lo menos en el discurso- fuesen iguales en derechos. Sin embargo, la implementación de estas ideas se enfrentó a la compleja realidad de sociedades que legitimaban sistemas discriminatorios y racistas con nítida jerarquización entre colonizadores, españoles-americanos, aborígenes y negros. Del mismo modo, las elites gobernantes que deseaban alcanzar los niveles y modo de vida de los centros desarrollados de Europa, lograr la modernización y la inclusión al sistema de Estados 'civilizados'; desconocieron las raíces precolombinas del continente.

Los proyectos de construcción estatal, con sus ideas y prácticas surgieron fundamentalmente a partir de los procesos de independencia durante el siglo XVIII y continuó hasta principios del siglo XX. Fue durante la llamada era liberal, tanto en Europa como en América Latina, que se promovieron estas ideas con diferentes resultados. Se advierte que la consolidación estatal fue más fácil en aquellos países donde había primacía de un centro urbano, ya que según Soifer (2016):

cuando varias ciudades aspiraban a un estatus nacional, tendían a surgir más puntos de vista de laissez-faire. Aquí, las diferencias regionales en las preferencias de los bienes públicos fueron más notables, lo que hizo que el estado desempeñara un rol limitado para el estado como una solución menos mala para las prioridades fiscales ${ }^{7}(20)$.

Por otro lado, y paralelamente al surgimiento de las nuevas repúblicas, se plantearon ideas integracionistas en América Latina con el fin de hacer frente a la amenaza de reconquista de parte de las exmetrópolis, como estrategia de

\footnotetext{
${ }^{7}$ Traducción propia.
} 
inserción internacional, búsqueda de autonomía y para consolidar un proyecto identitario (Rivarola y Briceño-Ruiz, 2013).

Francisco de Miranda, uno de los precursores de la emancipación hispanoamericana, a través del Acta de París (1797), explicitó su interés por establecer una unidad continental. Asimismo, José de San Martín como Líder del Ejército de Los Andes y luego en su calidad de Protector de la Libertad del Perú promovió el ideal integracionista. En 1818 envió una misiva al Director Supremo de Argentina manifestando el deseo de concretar una sola patria para los americanos. En la misma línea, Bernardo O'Higgins, Director Supremo de Chile, defendió la idea de establecer una federación de los pueblos de América en un manifiesto publicado en 1818. Idea acogida con entusiasmo por las Provincias Unidas de Centroamérica que en 1823 impulsaron una confederación general (Oyarzún y Astroza, 2012: 188).

De la misma manera se manifestó el Libertador Simón Bolívar, como se advierte en su correspondencia con otros líderes de la época, al igual que en su Manifiesto de Cartagena en 1812 o en la Carta de Jamaica de 1815, en las que se refiere a la posibilidad de emprender un proyecto de integración. También fue artífice de programas supranacionales como el establecimiento de la Gran Colombia (1819) o la Celebración del Congreso Anfictiónico de Panamá (1824-1826). No obstante, una vez consolidada la independencia "los nuevos Estados se enfrascaron en conflictos, algunos de los cuales aún no se han superado" (Gilhodes, 2003: 35). También se constata en la región, que post periodo independencia, no surgió un fuerte nacionalismo ni tampoco se alcanzaron los niveles de legitimidad que si existieron durante la Colonia.

Varios investigadores al evaluar el proceso de construcción del Estado en América Latina y su éxito o fracaso en base a su capacidad estatal, es decir a su fortaleza y poder territorial (monopolio del uso de la fuerza), de infraestructura, de poder económico y/o de poder simbólico (legitimidad y sentimiento de pertenencia) los vincula a las decisiones y prácticas que fueron adoptadas durante la era liberal (Soifer, 2016; Kurtz, 2013; Centeno y Ferraro, 2013). Del mismo modo, se advierte que la mayoría de los Estados latinoamericanos no 
han sido capaces de implementar leyes eficaces en sus territorios, en algunos países escasea el imperio de la ley, monopolio del uso de la fuerza, además de tener niveles muy altos de violencia y corrupción, con excepciones parciales como Chile y Costa Rica (Centeno y Ferraro: 2013).

\section{Globalización y sus efectos: región, (des) integración y nacionalismo}

En Relaciones Internacionales se ha instalado un debate que está lejos de concluir sobre el impacto de la globalización en el Estado, la soberanía y en las culturas e identidades nacionales. Se abren interrogantes sobre cuál es el tipo de comunidad más eficaz para la política y la democracia, reconociendo que individuos y grupos pueden tener diversas pertenencias a comunidades locales, redes regionales y globales. "Los Estados transnacionales deben compartir las lealtades de sus súbditos con otras autoridades regionales y de la sociedad mundial, por una parte y, por la otra, con autoridades subestatales y subnacionales" (Beck, 1998: 159).

Con base en los supuestos del idealismo en las Relaciones Internacionales, que reconoce la existencia de armonía de intereses y por lo mismo la posibilidad de cooperar entre diversos individuos y territorios (Arenal, 1994; Doyle, 1997), se promueve la construcción de comunidades políticas más amplias que el Estado, regiones supranacionales y organizaciones internacionales, con el fin de gestionar de manera eficaz los desafíos transnacionales. Las organizaciones internacionales y de integración se convierten en sujetos del derecho internacional, estableciendo vínculos entre ellas y con terceros. En este escenario, la región puede ser entendida como un subsistema supranacional del sistema internacional, con su propia dinámica. A juicio de Nye (1968), la región se compone de territorios geográficamente cercanos, cuyas políticas exteriores estarían interrelacionadas. En tanto, Russett (1967), da énfasis a la proximidad geográfica; interdependencia, especialmente en términos económicos y a la 
homogeneidad de valores. Según su desarrollo institucional y cohesión existen distintos tipos de regiones, algunas con mayor capacidad y competencias.

En el caso de procesos de integración, la región incluso puede contar con instituciones supranacionales, derecho comunitario y reconocimiento en el escenario internacional. La unión política permitiría que una mayor cantidad de personas compartan lealtades, desarrollando sentimientos de pertenencia e identidades comunes (Deutsch, 1971).

La integración es un fenómeno complejo y multidimensional por lo que resulta útil para el análisis distinguirla en tres áreas, una política, una económica y otra cultural. La integración política se asocia a la toma de decisiones y la búsqueda de cohesión, su agenda de investigación destaca los efectos de la globalización en el Estado, la vigencia de éste y su capacidad para responder adecuadamente a los desafíos actuales [...] proceso progresivo por el cual los actores nacionales cambian su lealtad y expectativas hacia una nueva organización supranacional. Requiere la intencionalidad política de los conductores del proyecto para impulsarlo y consolidarlo, si es exitoso culminará en la formación de una nueva comunidad sobre impuesta a las preexistentes (Oyarzún, 2008: 107).

Uno de los ejemplos más exitosos y revolucionarios, a raíz del cambio en las ideas y concepciones clásicas sobre la soberanía es la creación de la Unión Europea (UE), proceso de integración que hoy cuenta con 28 Estados miembros ${ }^{8}$. En sus orígenes, post Segunda Guerra Mundial y post Holocausto, partió solo con 6 países europeos, Francia, Alemania, Italia, Luxemburgo, Bélgica y Países Bajos y nació con el objetivo de evitar un nuevo conflicto armado, asegurar el bienestar de sus habitantes por medio de la construcción de un sistema multilateral y gestionar la interdependencia (Kaldor, 2012). Oyarzún y Astroza (2012), identifican cuatro factores que facilitaron su surgimiento: a) Las condiciones catastróficas en que quedaron los países europeos después de la guerra; b) La voluntad de los líderes

\footnotetext{
${ }^{8}$ Reino Unido inició el Brexit, proceso de desvinculación de la UE, luego que la mayoría de los ciudadanos británicos votó por esa opción en un referéndum realizado en 2016.
} 
que defendieron la estrategia de integración; c) La percepción de que la paz duradera solo sería posible a través de la integración y; d) La culminación del ciclo en que los poderes europeos son el centro de la sociedad internacional. A esos elementos, se debe agregar el escaso margen de decisión con el que contaba Alemania, después de su derrota militar.

En referencia a la integración europea, Haas (1966) señaló que dependiendo del momento histórico tanto las tendencias integradoras como desintegradoras cohabitan la nueva región. En la Comunidad Europea del Carbón y el Acero (CECA), creada en 1951 y antecedente de la hoy UE, se debió generar un proceso de cambio de las ideologías nacionales para permitir su evolución. Su construcción ha sido ardua, debido al complejo proceso de transferencia de lealtades por parte de las elites y los ciudadanos hacia un nuevo centro supranacional. En la etapa inicial "predomina en forma completa el nacionalismo en cada uno de los países participantes. Sin embargo, una vez que encuentran establecidas las instituciones asociadas a las medidas de integración es probable que se produzca un cambio" (Haas, 1966: 72).

Por otro lado, como respuesta ante la distribución desigual de ganancias, percepción de peligro para las identidades nacionales, étnicas y religiosas, asociadas a la mayor globalización, se advierten procesos de fragmentación y nacionalismo (Holsti, 1980). En este sentido, Centeno y Ferraro (2003) al estudiar el proceso de construcción estatal en América Latina, constataron que pese a que todos los países buscaron desarrollar formas de comunidad centrada en el Estado, se vieron enfrentados a fuertes y profundas divisiones raciales, de clase, entre las elites locales, de tradición histórica y con escasa capacidad de infraestructura. Aseguran que la fragmentación social y política ha sido una de las características dominantes de la región desde el comienzo de su historia moderna hasta nuestros días. "Las identidades colectivas que existen no son congruentes con el estadonación; a menudo se desarrollan en oposición a ella" (18). 
Tanto la integración como la desintegración representan un cambio de sistema que devela la tensión ante la globalización y el deseo de mantener la singularidad cultural de un pueblo específico (Sidjanski, 1998). En un mundo de flujos globales, la búsqueda de la identidad colectiva o individual, atribuida o construida, se convierte en la fuente fundamental de significado social (Castells, 2000).

En este escenario, diversos movimientos y nacionalismos locales y regionales desafían al Estado desde abajo, como sistema de poder representativo y eficiente. El nacionalismo puede manifestarse mediante las demandas de secesión (fragmentación) y de irredentismo (unificación). Se basa en un conjunto de valores e intereses comunes que une a ciudadanos que perciben su entorno como una amenaza, incomprensible e incierto, por lo que buscan predominio frente a otros. El nacionalismo puede fortalecer la voluntad común desarrollando capacidades cuasi gubernamentales o construyendo un Estado que tenderá a reducir o eliminar la influencia extranjera en algunos casos promoviendo conductas y/o normativas xenófobas (Holsti, 1980; Deutsch, 1971). Gurr (2001), analizando conflictos etnopolíticos, hace referencia a la idea de privación relativa para explicar el estallido social o los conflictos armados internos. Es decir, cuando una minoría nacional o un grupo marginado (por género, religión, raza, etnia, etc.) adquieren las mismas pretensiones del conjunto dominante y pese a sus reivindicaciones continúa siendo excluido.

Se distinguen tres fases en el nacionalismo, la primera asociada al principio de autodeterminación de las comunidades. La segunda fase está ligada a la Revolución Francesa y sus principios, destacándose la idea de igualdad de todos los ciudadanos; esta vertiente va ligada a la experiencia revolucionaria, el elemento consultivo y democrático, la nación se entiende como una construcción social de la voluntad común. La tercera fase, vinculada a la concepción romántica, principalmente de autores germanos, vertiente que destaca la tradición, la historia, legados de antepasados y cultura. La doctrina 
nacionalista va unida a la idea de nación, concepto que emerge a finales del siglo dieciocho y principios del diecinueve (Fermandois, 1992). La nación es la base moral del Estado que debe representar a la gente, admitiendo que las nacionespueblos existen y por lo tanto tienen derecho a la autodeterminación. Un pueblo se define en razón a características objetivas y subjetivas, pero principalmente a la voluntad de pertenecer a un colectivo. "Tanto el Pacto de la Sociedad de Naciones y la Carta de Naciones Unidas descansa en este supuesto, y de éste se deriva todo el sistema de derecho internacional" (Halliday, 2001: 447).

Por su parte, el nacionalismo: a) Provee de un sistema de valores y legitimación al sistema internacional; los Estados representan intereses de personas por lo que los grupos de personas tienen derecho a la autodeterminación; b) Genera identidad, transformándose en un componente fundamental para la construcción del Estado-nación. Exalta valores positivos hacia la patria, pueblo, nación y/o Estado en el núcleo familiar y en el sistema educacional, principalmente por medio de la enseñanza y medios de comunicación masivos; c) Justifica la secesión y unificación o irredentismo; d) Pero también puede provocar un conflicto armado, sobre todo si se combina nacionalismo, regímenes dictatoriales y políticas racistas y xenófobas (Halliday, 2001).

En la actualidad y a raíz de la mayor interdependencia, un grupo de individuos puede pertenecer a varias comunidades superpuestas, internacionales y/o domésticas. Por lo tanto, la lealtad no está asociada exclusivamente al territorio, coexistiendo una multiplicidad de roles-identidades. Por ejemplo: mujer, trabajadora, madre, hija, chilena, suramericana, latinoamericana, profesional, entre otros. Por medio de las interacciones, los actores reproducen identidades que paralelamente reflejan intereses que les llevan a adoptar elecciones de comportamiento (Wendt, 1999).

El caso latinoamericano no queda excluido de esta tendencia, diversas

9 Traducción propia 
identidades están en constante tensión con el Estado. "Podemos decir que lo $<<$ latinoamericano $>>$ anda suelto, desborda su territorio, va a la deriva en rutas dispersas" (García Canclini, 2002: 20). Así por ejemplo, algunas poblaciones indígenas reivindican su derecho como "pueblos" originarios, exigiendo autodeterminación. Con esto buscan mantener sus tradiciones, cosmovisión, territorio, autonomía política, representación, entre otras demandas. Si bien algunos Estados latinoamericanos han adoptado medidas para paliar la sensación de exclusión-opresión hacia estas comunidades, como por ejemplo ratificar el Convenio 169 de la Organización Internacional del Trabajo (OIT) que reconoce derechos básicos de los pueblos originarios, o incluir en sus cartas magnas el carácter plurinacional de sus sociedades, es un problema aun no resuelto ${ }^{10}$.

En este escenario, la región se presenta como una posibilidad de mediador y puente frente a las fuerzas globalizantes, un 'macrocuerpo' que contiene la representación política de varios 'microcuerpos' y que de acuerdo a las circunstancias, permite mediar la integración a entidades más amplias, operando la identidad en la diferencia ${ }^{11}$ (Auat, 2006). La región puede ser flexible y dinámica; los países latinoamericanos la han usado como organización política para mejorar su posición relativa en negociaciones multilaterales y profundizar su inserción internacional, ya que "esta última vía parece ser la única posible en un plazo razonable de tiempo" (Rios, 2005:17).

Los desafíos que presenta la globalización a las formas de representación

\footnotetext{
10 La Convención 169 de la OIT fue instaurada en 1989 y establece tanto los derechos como las responsabilidades de los Estados hacia los pueblos originarios. Promueve el respeto a la identidad propia de pueblos indígenas, la participación efectiva, el establecimiento de mecanismos apropiados para administrar programas que afecten a los interesados. Los puntos más polémicos de la convención tienen relación con el reconocimiento a la autodeterminación, ley consuetudinaria indígena y territorio. Algunos de los Estados latinoamericanos que han ratificado la Convención son: México (1990); Colombia (1991); Bolivia (1992); Costa Rica (1993); Paraguay (1993); Honduras (1994); Guatemala (1996); Ecuador (1998); Argentina (2000), Chile (2009). Véase: www.ilo.org

${ }^{11}$ La etimología de palabra región proviene del latín regio, que significa dirección, línea recta, horizonte, país, comarca, región, pero va asociado a la idea de dirigir, gobernar, regir (rego).
} 
política y cultural pueden abordarse desde la región al potenciar su construcción de manera flexible e integrativa de las diferencias. Gran parte del éxito de una organización regional se basa en adoptar una fórmula de exacta adecuación de las partes con el todo, un equilibrio que no confronte las unidades autónomas ni las diluya. Las interacciones horizontales entre regiones políticas puede convertirse en una herramienta efectiva para dar mayor gobernanza en la arena global (Meyer, 2012).

\section{Reflexiones finales: ¿Estado o Región?}

El Estado es un tipo de organización política que emergió en Europa durante el siglo XVII y hoy se ha convertido en el sistema dominante de la sociedad internacional. En tanto, la soberanía se constituyó en uno de sus principales atributos y principio estructurante del nuevo Orden Westfaliano. A través de este artículo, se estudiaron los efectos de la globalización en América Latina, particularmente en la concepción del Estado Westfaliano y de la soberanía, concluyendo que la globalización establece retos en dos planos, en primer término la representación del lugar desde donde se construyen las identidades y acciones. En segundo término, en las ideas sobre la soberanía y la representación política, balanceando valores universales e intereses particulares dentro de sistemas complejos que acentúan la asimetría de la distribución de poder (Auat, 2006).

Asimismo, fue posible observar que tanto las tendencias de integración como las de nacionalismo y fragmentación son respuestas ante el mismo fenómeno, la mayor interdependencia e incertidumbre del sistema. "La necesidad de buscar nuevas formas de cohesionar la comunidad de ciudadanos se impone frente a la ruptura de la correspondencia entre el mercado, el Estado nacional y la ciudadanía [...] alteradas ahora con la desterritorialización de la producción y de los mercados y la restricción del poder de los Estados 
nacionales" (Fleury, 2004: 69-70). Se advierte que "el verdadero desafío de los 'nuevos gobiernos' latinoamericanos es reinventar las instituciones más allá del Estado" (Negri y Cocco, 2006: 28).

De la misma forma, se establece que el Estado en el siglo XXI presenta una naturaleza post westfaliana en el sentido de reconocer que, en algunos casos, mantiene sus atributos esenciales, pero en otros presenta lo que Meyer (2012) denominó estatalidad transnacional. Es por ello, que surge la necesidad de implementar un control democrático en los temas en los que el Estado no tiene potestad, examinar el papel de las organizaciones, agencias y entidades regulatorias regionales y globales.

En ese contexto, y ante la pregunta sobre la vigencia del Estado y cuál es la organización más apropiada para la representación de individuos con lealtades superpuestas en comunidades internacionales y domésticas, se concluye que la emergencia de las regiones puede contribuir a la gobernanza regional y global. Sin embargo, esto no significa el fin del Estado y de la soberanía, sino más bien se propone una nueva forma de entenderlos, más flexible que permita concebirlo como una construcción social con capacidad de cambio y en coexistencia con organizaciones de carácter regional, algunas de ellas con capacidades supraestatales.

\section{Referencias}

Anderson, Benedict (1993). Comunidades Imaginadas. Reflexiones sobre el Origen y la Difusión del Nacionalismo. México, D.F. : Fondo de Cultura Económica.

Arenal, Celestino (1994). Introducción a las Relaciones Internacionales. Las Relaciones Internacionales como teoría y disciplina. Madrid: Tecnos.

Auat, Alejandro (2006). La región: mediación necesaria para una globalización no excluyente. En Adolfo Sequeira (Comp.), Globalización, región y liberación. Filosofia y pensamiento latinoamericano (pp. 17-25). Córdoba: Ediciones del Copista. 
Beck, Ulrich (1998) ¿Qué es la Globalización? Falacias del globalismo, respuestas a la globalización. Barcelona: Paidós.

Biersketer, Thomas (2008). State, Sovereignty, and Territory. In Walter Carslnaes, Thomas Risse y Beth Simmons (Eds.), Handbook of International Relations (pp. 157-175). Londres: Thousand Oaks, Nueva Deli y Singapur: SAGE Publication.

Caporaso, James (2000). "Change in the Westphalian Order. Territory, Public Authority and Sovereignty”. International Studies Review, 2 (2), 1-28.

Castells, Manuel (2000). La Era de la Información. Volumen 1. La Sociedad Red. Madrid: Alianza Editorial.

Centeno, Miguel A. y Ferraro, Agustín (eds.). (2013). State and Nation Making in Latin America and Spain. Cambridge: Cambridge University Press.

Christiansen, Thomas; Knud Jorgensen y Antje Wiener (Eds.). (2001). The Social Construction of Europe. London, Thousand Oaks y New Delhi: SAGE Publication.

Deutsch, Karl (1971). El Nacionalismo y sus Alternativas. Buenos Aires: Paidós.

Doyle, Michael (1997). Ways of War and Peace. Realism, Liberalism, and Socialism. New York: WW Norton \& Company.

Fermandois, Joaquín (1992). "Nación y Mundo Moderno: nacionalismo versus diversidad". Revista Universitaria, 37, 37-41.

Fleury, Sonia (2004). “Ciudadanías, exclusión y democracia”. Nueva Sociedad, 193 (septiembre-octubre), 62-75.

García Canclini, Néstor (2002). Latinoamericanos buscando lugar en este siglo. Buenos Aires, Barcelona, México: Paidós.

Gilhodes, Pierre (2003). América Latina, más que un concepto. En Aldo Olano (Ed.), América Latina: herencias y desafios (pp. 25-54). Bogotá: Universidad Externado de Colombia.

Gurr, Ted Robert (2001). Minorities and Nationalists: Managing Ethnopolitical Conflict in the New Century. In Chester Crocker, Fen Osler y Pamela 
Aall (Eds.), Turbulent Peace: The Challenges of Managing International Conflict (pp. 163-188). Washington: US Institute of Peace Press.

Haas, Ernst (1996). Partidos Políticos y grupos de presión en la integración europea. Buenos Aires: INTAL.

Haas, Ernst (2001). Does Constructivism Subsume Neo-Functionalism? In Thomas Christiansen, Jorgensen Knud y Wiener Antje (Eds.), The Social Construction of Europe (pp. 22-31). London, Thousand Oaks y New Delhi: SAGE Publication.

Halliday, Fred (2001). Nationalism. In John Baylis y Steve Smith (Eds.), The Globalization of World Politics (pp. 440-455). Oxford: Oxford University Press.

Held, David (1997). Democracia y Orden Global. Del Estado Moderno al Gobierno Cosmopolita. Madrid: Paidós.

Held, David y McGrew, Anthony (2003). Globalización/Antiglobalización. Barcelona: Paidós.

Hoffmann, Stanley (2002). "El estado de las cosas". Vanguardia Dossier, 3 (octubre-diciembre), 20-30.

Hoffmann, Stanley (1966). "Obstinate or Obsolate? The Fate of the NationState and the Case of Western Europe". Daedalus, 95, 862-915.

Holsti, Kalevi (2004). Taming the Sovereigns. Institutional Change in International Politics. Cambridge: Cambridge University Press.

Holsti, Kalevi (1980). Change in the International System: Interdependence, Integration, and Fragmentation. In Ole R. Holsti, Randolph M. Siverson y Alexander L. George (eds.), Changes in International System (pp. 2353). Boulder, Colorado: West View Press.

Iranzo, Ángela (2016). "Presentación: crisis migratorias y concepciones políticas del movimiento humano". Colombia Internacional, 88, 15-25.

Kaldor, Mary (2012). "La UE como nuevo tipo de autoridad política: el ejemplo de la política de seguridad". Revista Cidob d'Affairs Internacionals, 100, 113-130. 
Keohane, Robert y Nye, Joseph (2000). "Globalization: What's New? What's not? (And so What)". Foreign Policy, Spring, 104-119.

Krasner, Stephen (2001). Soberanía, hipocresía organizada. Barcelona: Paidós.

Kurtz, Marcus (2013). Latin America State Building in Comparative Perspective. Cambridge: Cambridge University Press.

Kymlicka, Will (2006). Fronteras Territoriales. Una perspectiva liberal igualitarista. Madrid: Trotta.

Lynch, John (2001). América Latina, entre colonia y nación. Barcelona: Editorial Crítica.

Meyer, Thomas (2012). Globalization, regionalization and stateness. In Mario Telò (Ed.), State, Globalization and Multilateralism (pp. 119-136). New York: United Nations University Series; Springer.

Negri, Antoni y Cocco, Giuseppe (1968). Global: biopoder y luchas en una América Latina globalizada. Buenos Aires: Paidós.

Nye, Joseph (1968). "Comparative Regional Integration: Concept and Measurement”. International Organization, 22 (4), 855-880.

Oyarzún, Lorena (2011)،“La Integración regional en América Latina: su papel como proyecto identitario, de construcción de comunidad y de gobernanza autónoma". Tesis Doctoral Inédita. España: Universidad Autónoma de Barcelona.

Oyarzún, Lorena y Astroza, Paulina (2012). La integración latinoamericana y europea en perspectiva histórica. De diferencias y similitudes en los procesos. En Europa-América Latina. Dos caminos ¿un destino común? (pp. 185-216). Concepción: RIL Editores y Programa de Estudios Europeos de la Universidad de Concepción.

Oyarzún, Lorena (2008). "Sobre la naturaleza de la integración regional: teorías y debates". Revista de Ciencia Política, 28 (3), 95-113.

Rios, Sandra (2005) ¿Globalización o Fragmentación de la Integración en América Latina? En Antoni Estevadeordal y Ramón Torrent (eds.), Regionalismo Global. Los dilemas para América Latina (pp. 17-43). Barcelona: Fundación CIDOB. 
Rivarola, Andrés y Briceño, José (eds.). (2013). Resilience of Regionalism in Latin America and the Caribbean: Development and Autonomy. New york: Palgrave Macmillan.

Russett, Bruce (1967). International Regions and the International System. A Study in Political Ecology. Chicago: Rand McNally.

Sidjanski, Dusan (1998). El futuro federalista de Europa. De los origenes de la Comunidad Europea a la Unión Europea. Barcelona: Editorial Ariel.

Soifer, Hillel (2016). State Building in Latin America. Cambridge: Cambridge University Press.

Stiglitz, Joseph (1992). El Malestar en la globalización. Buenos aires: Editorial Taurus.

Stuven, Ana (1992). "Hispanoamérica y el espíritu nacional: múltiples recorridos". Revista Universitaria, 37, 42-47.

Wendt, Alexander (1987). "The Agent-Structure Problem in International Relations Theory". International Organization, 41 (3), 335-370.

Wendt, Alexander (1999). Social Theory of International Politics. Cambridge: Cambridge University Press. 